\title{
Proteomic analysis of serum deprivation in tongue squamous cell carcinoma
}

\author{
JUNFENG ZHANG $^{1}$, WEI DONG ${ }^{1}$, YUFEN MENG $^{1}$, MIAO JIANG $^{2}$ and ZHEN ZHAN ${ }^{1}$ \\ ${ }^{1}$ Discipline of Chinese and Western Integrative Medicine, School of Medicine and Life Sciences; \\ ${ }^{2}$ College of Chinese Medicine, Nanjing University of Chinese Medicine, Nanjing, Jiangsu 210023, P.R. China
}

Received October 10, 2016; Accepted June 6, 2017

DOI: $10.3892 / \mathrm{mmr} .2017 .7807$

\begin{abstract}
The occurrence of tongue squamous cell carcinoma (TSCC) is closely correlated with serum components; however, the detailed mechanism remains to be fully elucidated. Proteomic analysis contributed to the discovery of potential biomarkers and provided an insight into TSCC at a molecular level. The present study investigated the effect of serum deprivation on the Tca-8113 TSCC cell line through protein profiling using two-dimensional gel electrophoresis and mass spectrometry, with the aim of improving TSCC diagnosis. The results showed that the Tca-8113 cells maintained proliferative capacity and resisted apoptosis following serum deprivation. A total of 43 proteins were upregulated and 45 were downregulated following serum deprivation for $24 \mathrm{~h}$, compared with untreated controls $(0 \mathrm{~h})$. The upregulated caspase-7, heat shock protein 27 and Annexin A1, and the downregulated peroxiredoxin- 6 and heat shock protein 70 , were selected for verification using reverse transcription-polymerase chain reaction analysis following serum deprivation for $16 \mathrm{~h}$. The results indicated that reactive oxygen species may be important in serum deprivation-induced oxidative stress.
\end{abstract}

\section{Introduction}

Tongue squamous cell carcinoma (TSCC) has a particularly high mortality rate among malignancies, predominantly due to the difficulty of early detection, and its incidence is increasing rapidly according to the American Cancer Society $(1,2)$. Studies have shown that TSCC has a poorer prognosis and higher recurrence rate, compared with several other types of cancer due to metastasis being common (3). Clinical results suggest that a lack of available biomarkers

Correspondence to: Dr Junfeng Zhang, Discipline of Chinese and Western Integrative Medicine, School of Medicine and Life Sciences, Nanjing University of Chinese Medicine, 138 Xianlin Avenue, Nanjing, Jiangsu 210023, P.R. China

E-mail: zhangjunfeng5_5@163.com

Key words: tongue squamous cell carcinoma, serum deprivation, protein profiling result in the majority of patients with TSCC not being diagnosed until an advanced stage. Therefore, understanding the molecular basis of tongue carcinogenesis may provide potential molecular markers for more rapid diagnosis of TSCC. Several biological molecules have been reported in the saliva and serum, and histological analysis has indicated that they are useful for screening and early detection of several types of cancer (4-6).

Serum is important for supporting cell viability and $\mathrm{pH}$ maintenance (7), whereas saliva is important in oral hygiene, food digestion and the repair of mucosal damage, as demonstrated by animal behavioural experiments and in vivo analysis of patients (8). Studies have suggested that saliva and serum are functionally similar and reflect the physiological state of the body (9-11), and that saliva is a non-invasive sample for potential clinical diagnosis. In the present study, serum deprivation experiments were performed on the Tca-8113 TSCC cell line to screen for potential biomarkers suitable for TSCC diagnosis. This was based on previous observations that serum deprivation synchronises proliferating cells at the G0 phase, induces apoptosis and stimulates the fibrotic response (12).

The results of the present study showed that the Tca-8113 cells resisted serum deprivation-induced apoptosis. Two-dimensional gel electrophoresis (2-DE) and mass spectrometry-based protein identification were used for the proteomic analysis of serum-deprived Tca- 8113 cells. The results provided insight for potential diagnostic biomarkers or drug targets for the treatment of TSCC.

\section{Materials and methods}

Cell culture and MTT assay. The cells were routinely cultured, and MTT (Sigma-Aldrich; Merck KGaA, Darmstadt, Germany) assays were performed as previously described (13). Briefly, the TSCC Tca-811 cell line, provided by the Ninth People's Hospital of Shanghai (Shanghai, China) was maintained by routine culturing in RPMI-1640 medium with $10 \%$ fetal bovine serum (FBS) (both from Gibco; Thermo Fisher Scientific, Inc., Waltham, MA, USA) in a $37^{\circ} \mathrm{C}$ incubator with $5 \% \mathrm{CO}_{2}$. The cells were digested with $0.25 \%$ trypsin and seeded into 96 -well plates (cat no. 3524; Corning Incorporated, Corning, NY, USA) at a density of $1 \times 10^{4}$ cells/well and cultured for $18-24$ h to $90 \%$ confluence. 
Table I. Reverse transcription-polymerase chain reaction primer sequences for the six genes.

\begin{tabular}{ll}
\hline Gene & \multicolumn{1}{c}{ Primer sequence } \\
\hline Annexin A1 & F: 5'-AAGACTTGGCTGATTCAGATGC-3' \\
& R: 5'-AACACTCTGCGAAGTTGTGGATA-3' \\
Peroxiredoxin 6 & F: 5'-CGCATCCGTTTCCACGACTT-3' \\
& R: 5'-TGGCAAGCTCCCGATTCCTAT-3' \\
Heat shock protein 27 & F: 5'-AGTGGTCGCAGTGGTTAGGC-3' \\
& R: 5'-GGTTGACATCCAGGGACACG-3' \\
Heat shock protein 70 & F: 5'-CTGCTGCGACAGTCCACTACC-3' \\
& R: 5'-TCGGCTCCGCTCTGAGATT-3' \\
Caspase-7 & F: 5'-GAAGAGGCTCCTGGTTTGTG-3' \\
& R: 5'-CTGGCAACTCTGTCATTCACC-3' \\
GAPDH & F: 5'-GGGAAACTGTGGCGTGAT-3' \\
& R: 5'-GAGTGGGTGTCGCTGTTGA-3' \\
\hline
\end{tabular}

GAPDH, glyceraldehyde phosphate dehydrogenase; F, forward; R, reverse.

Serum deprivation was performed following washing twice with PBS. The cells were cultured for 12, 24, 36, 48 and $72 \mathrm{~h}$ following serum deprivation in the media at $37^{\circ} \mathrm{C}$, with $10 \%$ serum as a control. Following cell culture, the culture medium were discarded, $200 \mu 1$ of $0.5 \mathrm{mg} / \mathrm{ml}$ MTT in PBS was added to wells, and the cells were cultured for $4 \mathrm{~h}$ at $37^{\circ} \mathrm{C}$. Following removal of the supernatants, $200 \mu \mathrm{l}$ of DMSO was added and cells were shaken lightly for $15 \mathrm{~min}$. The optical density value was measured using a microplate spectrophotometer (POWERWAVE 340; BioTek Instruments, Inc., Winooski, VT, USA) at $490 \mathrm{~nm}$. All experiments were repeated four times and the mean \pm standard deviation of results were calculated.

Proteomic analysis. The proteomic experiments were performed as described previously (14). The steps were as follows: i) At least $1.0 \times 10^{8} \mathrm{Tca}-8113$ cells were harvested and lysed for sample preparation, and the bicinchoninic acid method was used for measurement of protein concentration; ii) each $80 \mu \mathrm{g}$ sample was subjected to 2-DE on an Ettan IPGphor II apparatus (GEHealthcare Life Sciences, Chalfont, UK) in triplicate. Silver-stained gels were scanned at 300 dpi resolution, and differential analysis was performed to assign spots. Student's t-test was used for filtering, and spots with a fold-change $>1.2$ were considered differentially expressed; iii) selected spots were subjected to MALDI-TOF mass spectrometry and tandem TOF/TOF mass spectrometry. The identified peptides were used for Basic Local Alignment Search Tool searches of the International Protein Index rat sequence database (http://www.matrixscience.com). The protein number, protein name, sequence coverage, score and $\mathrm{Mr} / \mathrm{pI}$ were obtained and included in the analysis.

Reverse transcription-quantitative polymerase chain reaction (RT-qPCR) analysis. The serum-deprivation treated Tca-8113 cells were prepared for one-step RT-qPCR SYBR Green assay as previous described (15). Briefly, RNA was extracted using the TRIzol LS reagent and the cDNA Synthesis kit (both from
Gibco; Thermo Fisher Scientific, Inc.) was used for cDNA synthesis. A total of $1 \mu 1$ reverse transcriptase product was used to amplify the six genes (Annexin A1, peroxiredoxin 6, heat shock protein 27 , heat shock protein 70 , caspase-7 and GAPDH). Primers (Table I) were designed based on the sequences of the five differentially expressed proteins identified in the proteomic analysis and GAPDH gene was used as reference. The primers were synthesized by Sangon Biotech (Shanghai) Co., Ltd. (Shanghai, China). The SYBR Green Real-Time PCR Master Mix (TOYOBO; Toyobo Life Science, Inc., Osaka, Japan) was used and the PCR cycling parameters were as follows: $94^{\circ} \mathrm{C}$ for $30 \mathrm{sec}$, followed by 35 cycles of $60^{\circ} \mathrm{C}$ for $30 \mathrm{sec}$ and $72^{\circ} \mathrm{C}$ for $30 \mathrm{sec}$. A MyCycler thermal cycler (Bio-Rad Laboratories, Inc., Hercules, CA, USA) was used for the PCR analysis. Each gene was quantified by $2^{-\Delta \Delta \mathrm{Cq}}$ method (16) and the relative expression level was calculated by the ratio of each targeted gene to GAPDH gene.

Statistical analysis. Data are reported as the mean \pm standard deviation, and Student's t-tests were performed using the SPSS 16.0 software package (SPSS, Inc., Chicago, IL, USA). $\mathrm{P}<0.05$ was considered to indicate a statistically significant difference.

\section{Results}

Serum deprivation inhibits cell proliferation. Serum deprivation inhibited the proliferation of cells, as exhibited in Fig. 1. When the Tca- 8113 cells were subjected to serum deprivation for $12,24,36,48$ or $72 \mathrm{~h}$, the proliferative activity was measured using an MTT assay. No significant differences were observed over time in the serum-deprived group $(\mathrm{P}>0.05)$, however, proliferation continued to increase in the cells cultured in $10 \%$ FBS medium $(\mathrm{P}<0.05)$.

Identification of differentially expressed proteins using proteomic analysis. As proliferation was inhibited in the Tca- 8113 cells subjected to serum deprivation for $24 \mathrm{~h}$, the 


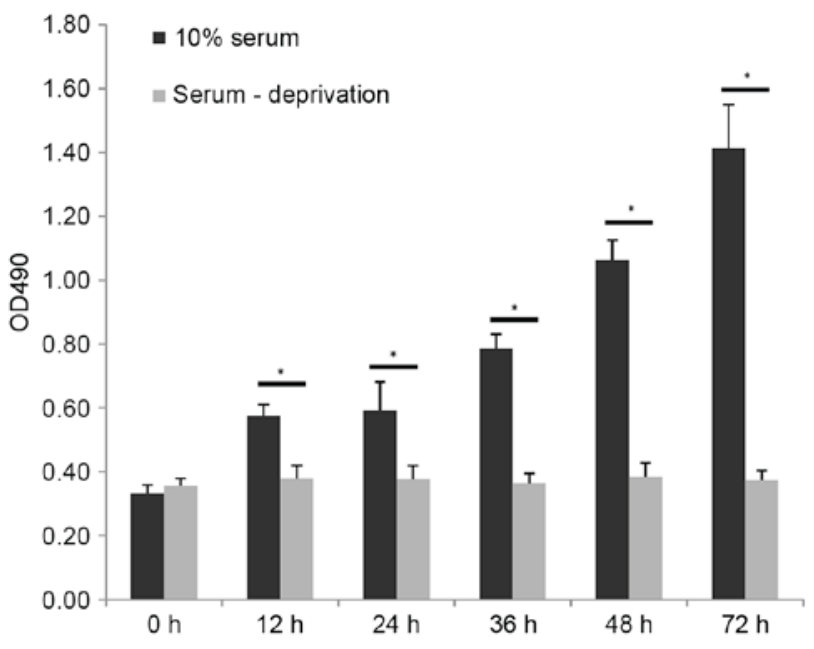

Figure 1. Proliferative activity of Tca- 8113 cells subjected to serum deprivation. Experiments were repeated four times. ${ }^{*} \mathrm{P}<0.05$.

time-points of $0 \mathrm{~h}$ (control) and $24 \mathrm{~h}$ were selected for the comparison of triplicate samples using 2-DE and mass spectrometry. Representative 2-DE images are shown in Fig. 2. A total of 1,237 protein spots were detected on the 2-DE gel, with 43 significantly upregulated and 45 significantly downregulated at $24 \mathrm{~h}$, compared with levels at $0 \mathrm{~h}(\mathrm{P}<0.05$; average spot intensity difference $>1.2$-fold). Of these 88 potential differentially expressed proteins, 35 were identified using MALDI-TOF/MS, whereas the remaining 53 did not yield suitably complete polypeptide fragments or were too low in abundance for reliable identification. The results of the spot ID, average spot intensity, protein number, protein name, sequence coverage, score and $\mathrm{Mr} / \mathrm{pI}$ are exhibited in Table II. The present study focussed on five differentially expressed proteins: Caspase-7 (spot 70), heat shock protein 27 (HSP 27; spot 390), Annexin A1 (spot 560), peroxiredoxin-6 (spot 405) and HSP 70 (spot 1194; Fig. 3). Notably, all are involved in mitochondrial oxidative stress, consistent with a previous conclusion that serum deprivation can induce apoptosis (7).

RT-PCR verification. The present study performed RT-PCR analysis to investigate the expression of caspase-7, HSP 27,
Annexin A1, peroxiredoxin-6 and HSP 70 in the Tca-8113 cells subjected to serum deprivation at two time-points ( 0 and $16 \mathrm{~h}$ ). The stably expressed GAPDH mRNA was selected as an internal reference gene as the expression of cytoskeletal proteins was significantly disrupted. For example, the expression of $\beta$-actin was increased at the protein (Table II) and mRNA levels (data not shown), whereas the expression of tubulin was decreased (Table II). As shown in Fig. 4, the expression patterns of the five proteins were similar to the results obtained using $2-\mathrm{DE}$.

\section{Discussion}

Serum deprivation is widely used for cell cycle arrest and apoptosis, and various molecular mechanisms may be involved in the modulation of serum deprivation-induced apoptosis (17). However, in the present study, the effects of serum deprivation on cell proliferation and apoptosis were not observed in the Tca-8113 cells, even following a long duration (72 h) of treatment (Fig. 1). The proteomic analysis showed that a $24 \mathrm{~h}$ period of serum deprivation induced significant expression changes of numerous mitochondrial proteins, including prohibitin, peroxiredoxin, glyoxalase, caspase and ATP synthase (Table II). This is consistent with a previous study, in which mitochondrial function was readily disrupted by alterations of the cultivation environment through serum deprivation, which affects mitochondrial viability in several fibroblast lines (18). However, the detailed molecular mechanism linking culture conditions and mitochondrial activity remains to be fully elucidated. The results of the present study provided novel insight into the mechanism by which Tca-8113 cells subjected to serum deprivation avoid apoptosis.

Although the mechanism by which serum deprivation stimulates reactive oxygen species (ROS) production remains to be elucidated, studies have shown that ROS resulting from serum deprivation can induce programmed cell death $(7,19)$. Oxidative stress has a wide range of effects on cellular proliferation, differentiation, migration and other physiological processes (20). Several antioxidant proteins are involved in alleviating oxidative stress by removing ROS. The present study found that peroxiredoxin-2 (Prx2) was upregulated, whereas the associated Prx6 was downregulated following

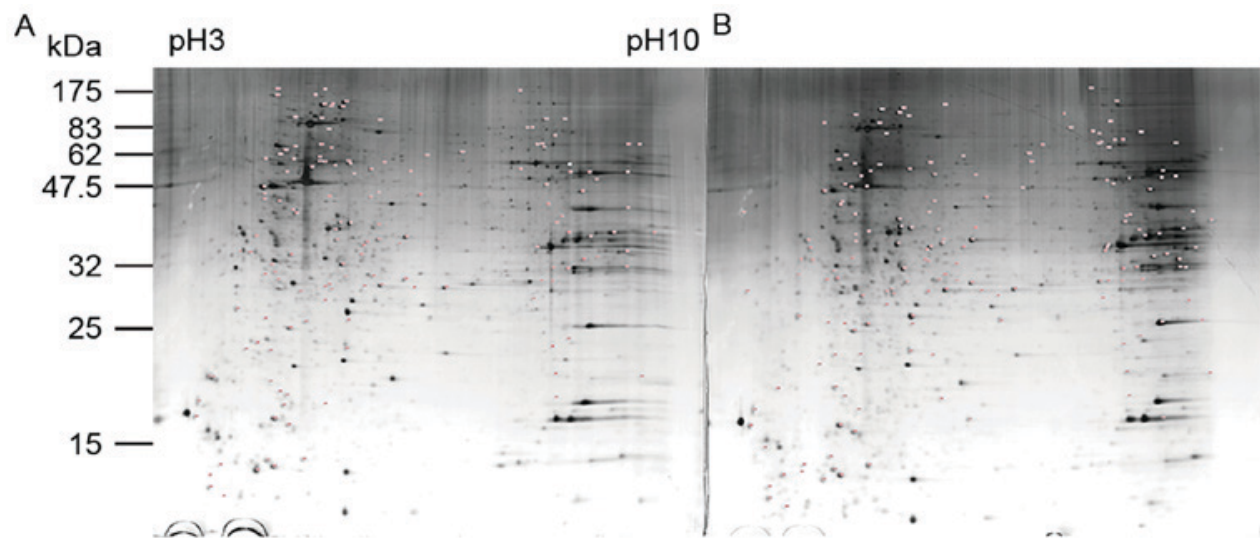

Figure 2. Typical silver-stained 2-DE polyacrylamide gel. Numbers refer to differentially expressed protein spots in Tca-8113 cells subjected to serum deprivation for (A) $0 \mathrm{~h}$ and (B) and $24 \mathrm{~h}$. 


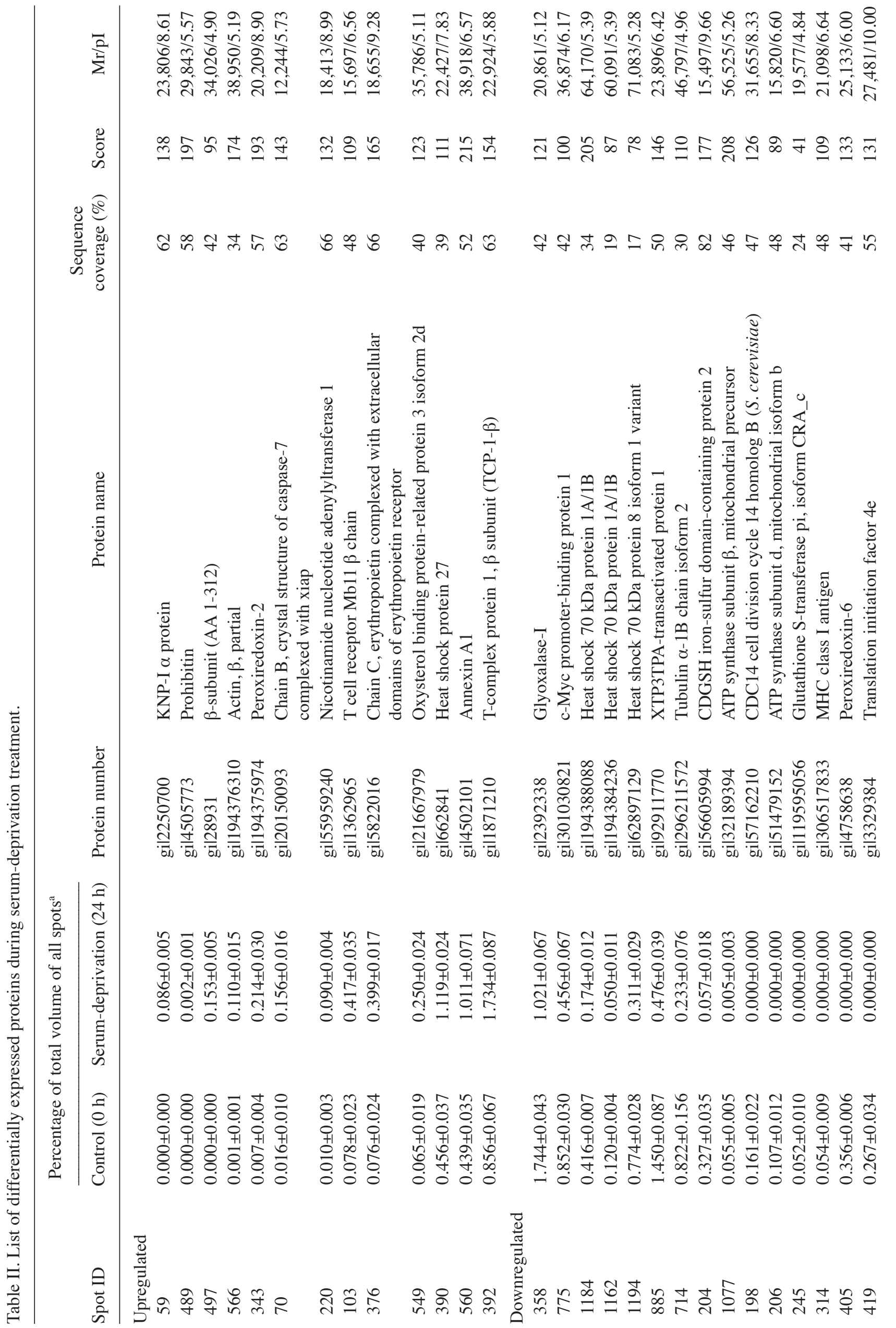




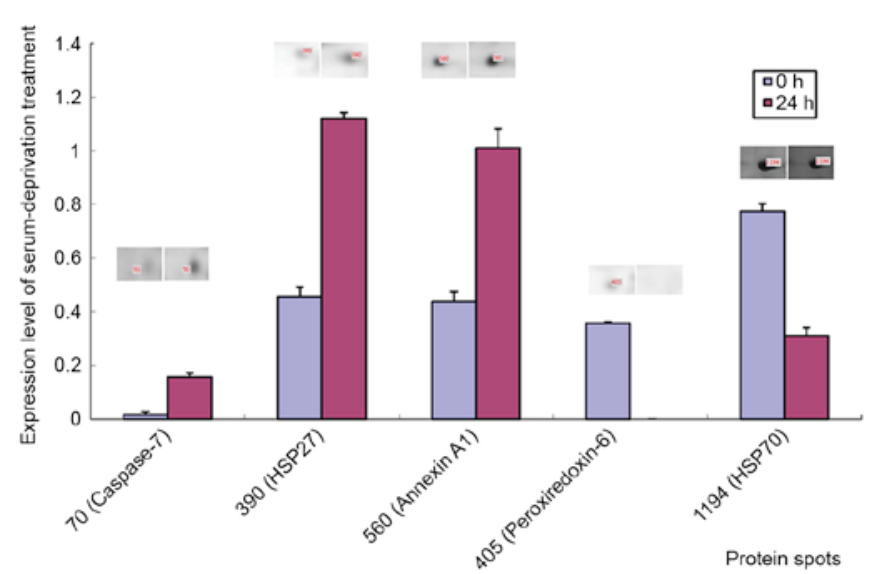

Figure 3. Mean relative abundance of five selected differentially expressed proteins (data extracted from Table II and Fig. 2).

serum deprivation. Prx enzymes have six isoforms, and they are located at sites of energy production and cellular motion, where ROS can be produced in abundance, particularly in mitochondria and at the plasma membrane. The peroxiredoxins are known for their function in removing endogenous peroxides. Therefore, the upregulation of peroxiredoxins is linked to high levels of oxidative stress (21). Prx 2 is the major Prx enzyme in the cytoplasm, where it reduces peroxynitrite and hydroperoxides via a rapid, diffusion-controlled reaction (22). Prx2 is also important in the mechanism of $\mathrm{H}_{2} \mathrm{O}_{2}$-induced redox signalling (23). The overexpression of Prx2 has been associated with the progression of squamous cell carcinoma, and it may be an underlying biomarker for radiotherapy in colorectal cancer (24) lung cancer (25) and bladder cancer (26). Similarly, the expression of Prx6 has been associated with high rates of metastasis of breast cancer cell lines, and the overexpression of Prx6 occurs in malignant mesothelioma, breast cancer, oesophageal carcinoma and oligodendroglioma (27). A previous study revealed a marked upregulation of Prx2 following demethylation in gefitinib-resistant A549 cells (28). The present results suggested that Tca- 8113 cells may resist the serum deprivation-induced apoptosis by upregulating Prx2, which may serve as a potent target for assisting in anti-angiogenic drug treatment in human TSCC.

Annexin A1 (ANXA1) is a well-characterised apoptosis-associated membrane protein, which is regulated by the epidermal growth factor receptor, insulin receptor, TRPM7 channel kinase 1, protein kinase $\mathrm{C}$ and protein kinase $\mathrm{A}$. ANXA1 has also been linked with carcinogenesis and metastasis in various types of tumour (29). As an essential protein in tumourigenesis and apoptosis, the overexpression of ANXA1 is linked to carcinogenesis and high pathological differentiation grade $(30,31)$. There is accumulating evidence suggesting that ANXA1 may be regulated by pro-inflammatory proteins, including lipopolysaccharide and interleukin-6, and it is reported to act as a brake to control the inflammatory response (32). Kang et al found that ANXA1 was positively upregulated during serum deprivation-induced autophagic degradation in HCT116 cells, indicating a potential role in autophagy by downregulating the inflammatory response (33). The overexpression of ANXA1 can also inhibit the aberrant dysregulation of cytoskeletal proteins and proliferation of 

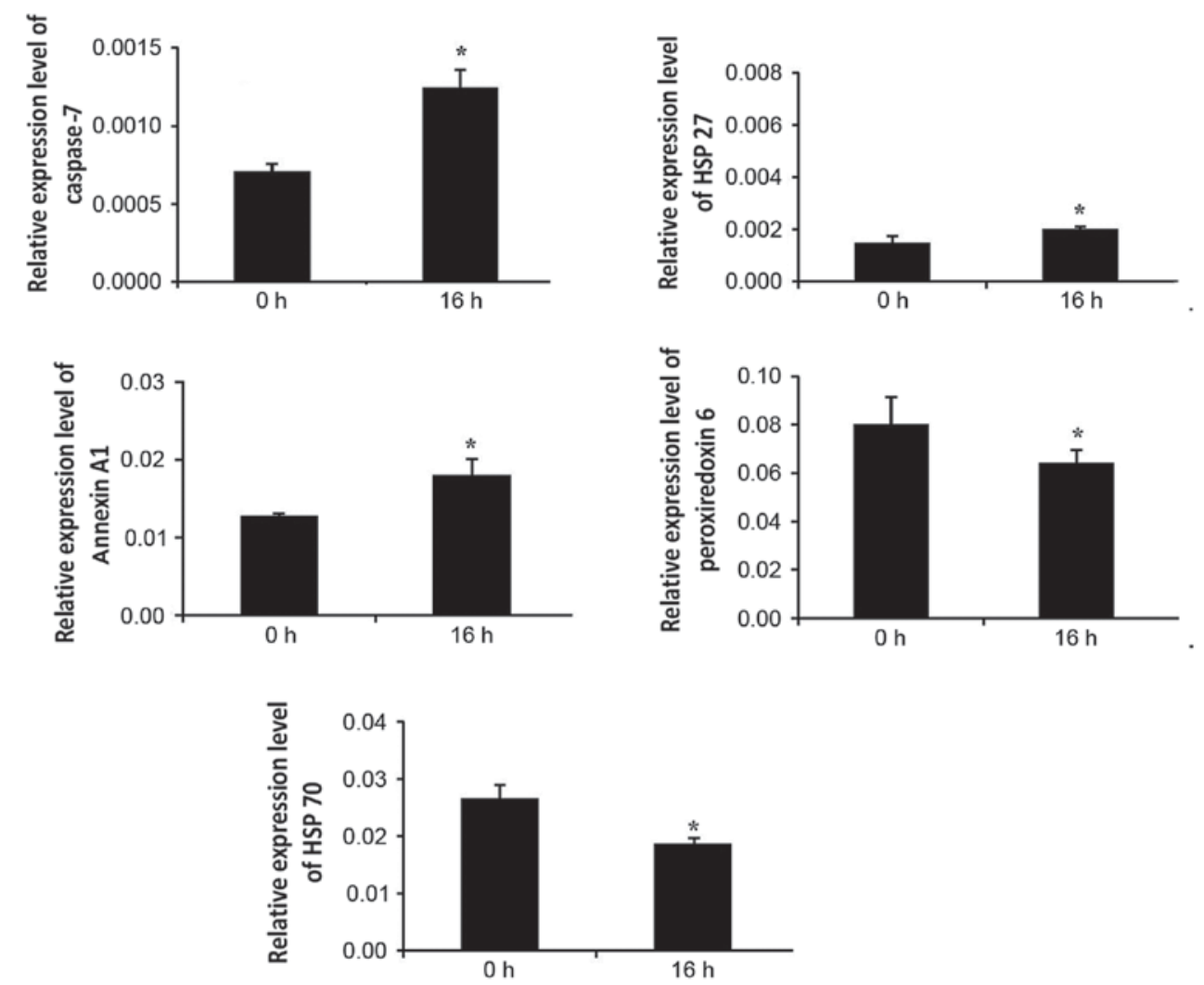

Figure 4. Verification of five selected differentially expressed proteins by reverse transcription-polymerase chain reaction analysis of mRNA levels following $16 \mathrm{~h}$ serum-deprivation. The relative expression levels of the mRNA were measured with GAPDH as reference. Experiments were repeated three times with similar results. " $\mathrm{P}<0.05$ vs. $0 \mathrm{~h}$

pulmonary microvascular endothelial cells (34), which is consistent with the observed morphology, static proliferation and upregulation of actin in the serum deprived Tca-8113 cells in the present study. The results of the present study showed that ANXA1 was upregulated at the mRNA and protein levels following serum deprivation, suggesting that autophagy, and not apoptosis, was a factor in Tca-8113 cells; autophagy protected the cells against serum deprivation by promoting cell survival.

Autophagy and apoptosis are the two major cell death pathways, and are tightly regulated at the genetic level to ensure that tissue and organ development proceeds correctly, in addition to other pathophysiological processes (35). A hallmark of autophagy is lysosomal degradation, which performs an adaptive function to protect organisms against infections, cancer and ageing (36). Apoptosis is a programmed process for killing and removing certain cells during morphological development, which also assists in maintaining tissue homeostasis in multicellular organisms. The aberrant regulation of apoptosis has been consistently linked with human proliferative diseases, including malignant tumours (37). Apoptosis involves a large number of molecules, including cysteine proteases in the form of caspases, which are synthesised as pro-forms and become activated by cleavage at aspartate residues. Initiator caspases, including caspase-1, 2, 4, 5, 8, $9,10,11$ and 12, integrate molecular signals and activate downstream effector caspases, including caspase-3, 6, 7 and 14. As caspases can cleave and activate each other, triggering of the caspase cascade initiates a rapidly amplified signal, which ensures accurate apoptotic cell death. Caspases are also able to cleave several other substrates, including nuclear lamins and cytoskeletal proteins, thereby inducing typical morphological characteristics associated with apoptosis. Caspase-7 is most closely linked with caspase-3, and these enzymes are activated by mitochondria-induced apoptosis.

Effector caspases are in charge of initiating DNA fragmentation, cell shrinkage and membrane blebbing (38). Brentnall et al (39) showed that caspase-9 and caspase-3 are involved in remodeling of mitochondria and ROS production. Caspase-7 has no significant effect on sensitivity to intrinsic cell death, but is involved in ROS production and cell detachment. In the present study, serum deprivation upregulated the level of caspase-7 in Tca-8113 cells, which underwent shrinkage and membrane blebbing, suggesting that serum deprivation stimulated TSCC differentiation and inhibited cancer growth.

HSPs are also closely linked with stress responses, including the response to serum deprivation. HSP70 is a major stress-inducible protein, which can fulfil multiple roles depending on its location. The upregulation of intracellular HSP70 is involved in the stress associated with recovery from clinical treatment, including radiotherapy or chemotherapy, whereas extracellular HSP70 stimulates the innate immune system to initiate antitumour immunity (40). In the present study, the serum deprivation-induced downregulation of HSP70 may assist TSCCs to escape and evade attacks from natural killer (NK) cells, however, the 
downregulation of major histocompatibility complex-I can compensate for this and ensure activation of the NK cells.HSP27 is primarily involved in proteasome-mediated protein degradation and the regulation of apoptosis. A previous study revealed that HSP27 mediates apoptotic programming in pancreatic cancer cells (41), and clinical immunohistochemical evidence demonstrates that the overexpression of HSP27 causes high-grade differentiation in TSCCs (42). Therefore, the serum deprivation-induced upregulation of HSP27 may be correlated with the morphology and differentiation of TSCCs, consistent with the expression of caspase-7.

In conclusion, the present investigative preclinical study found that Tca-8113 TSCC cells resisted apoptosis induced by serum deprivation. The changes in proteins were primarily involved in the oxidative stress process in the mitochondrion, which indicated that ROS may be important in serum deprivation-induced oxidative stress. In the future, further detailed investigations on the signalling pathway and clinical verification are required.

\section{Acknowledgements}

The authors would like to thank the Natural Science Foundation of China (grant nos. 81473593 and 81473458), the Jiangsu Qing Lan Project (grant no. QL-2014) for financial support, and the Priority Academic Program Development of Jiangsu Higher Education Institutions (Integration of Chinese and Western Medicine; grant no. PAPD-2014) for funding.

\section{References}

1. Ching CT, Sun TP, Huang SH, Hsiao CS, Chang CH, Huang SY, Chen YJ, Cheng CS, Shieh HL and Chen CY: A preliminary study of the use of bioimpedance in the screening of squamous tongue cancer. Int J Nanomed 5: 213-220, 2010

2. Jemal A, Siegel R, Ward E, Hao Y, Xu J and Thun MJ: Cancer statistics, 2009. CA Cancer J Clin 59: 225-249, 2009

3. Layland MK, Sessions DG and Lenox J: The influence of lymph node metastasis in the treatment of squamous cell carcinoma of the oral cavity, oropharynx, larynx, and hypopharynx: N0 versus N+. Laryngoscope 115: 629-639, 2005.

4. Korostoff A, Reder L, Masood R and Sinha UK: The role of salivary cytokine biomarkers in tongue cancer invasion and mortality. Oral Oncol 4: 282-287, 2011.

5. Faratzis G, Tsiambas E, Rapidis AD, Machaira A, Xiromeritis K and Patsouris E: VEGF and ki 67 expression in squamous cell carcinoma of the tongue: An immunohistochemical and computerized image analysis study. Oral Oncol 45: 584-588, 2009

6. Patel RS, Clark JR, Dirven R, Wyten R, Gao K and O'Brien CJ: Prognostic factors in the surgical treatment of patients with oral carcinoma. Anz J Surg 79: 19-22, 2009.

7. Lee SB, Kim JJ, Kim TW, Kim BS, Lee MS and Yoo YD: Serum deprivation-induced reactive oxygen species production is mediated by Romol. Apoptosis 15: 204-218, 2010.

8. Grossman N, Binyamin LA and Bodner L: Effect of rat salivary glands extracts on the proliferation of cultured skin cells-a wound healing model. Cell Tissue Bank 4: 205-212, 2004.

9. De Giuseppe R, Cossellu G, Vigna L, Dicorato F, De Vita C, Venturelli G, Bamonti F, Maiavacca R and Farronato G: Correlation between salivary and serum oxidized LDL levels: A pilot study on overweight/obese subjects. J Oral Pathol Med 44: 884-887, 2015.

10. Hayes LD, Sculthorpe N, Herbert P, Baker JS, Hullin DA, Kilduff LP and Grace FM: Poor levels of agreement between serum and saliva testosterone measurement following exercise training in aging men. Aging Male 18: 67-70, 2015.

11. Seethalakshmi C, Koteeswaran D and Chiranjeevi V: Correlation of serum and salivary biochemical parameters in end stage renal disease patients undergoing hemodialysis in pre and post-dialysis state. J Clin Diagn Res 12: CC12-CC14, 2014.
12. Boraldi F, Annovi G, Paolinelli-Devincenzi C, Tiozzo R and Quaglino D: The effect of serum withdrawal on the protein profile of quiescent human dermal fibroblasts in primary cell culture. Proteomics 8: 66-82, 2008.

13. Li WZ, Wang XY, Li ZG, Zhang JH and Ding YQ: Celecoxib enhances the inhibitory effect of cisplatin on Tca8113 cells in human tongue squamous cell carcinoma in vivo and in vitro. J Oral Pathol Med 7: 579-584, 2010.

14. Wu J, Wang F, Gong Y, Li D, Sha J, Huang X and Han X: Proteomic analysis of changes induced by nonylphenol in Sprague-Dawley rat Sertoli cells. Chem Res Toxicol 22: 668-675, 2009.

15. Cheuk BL and Cheng SW: Annexin A1 expression in atherosclerotic carotid plaques and its relationship with plaque characteristics. Eur J Vasc Endovasc Surg 41: 364-371, 2011.

16. Livak KJ and Schmittgen TD: Analysis of relative gene expression data using real-time quantitative PCR and the 2(-Delta Delta C(T)) method. Methods 25: 402-408, 2001.

17. Yuan F, Cheng Q, Li G and Tong T: Nucleostemin knockdown sensitizes hepatocellular carcinoma cells to ultraviolet and serum starvation-induced apoptosis. PLoS One 10: e0141678, 2015.

18. Takeda K, Akagi S, Takahashi S, Onishi A, Hanada H and Pinkert CA: Mitochondrial activity in response to serum starvation in bovine (Bos taurus) cell culture. Cloning Stem Cells 4: 223-229, 2002.

19. Liu J and Du L: PERK pathway is involved in oxygen-glucose-serum deprivation-induced NF-kB activation via ROS generation in spinal cord astrocytes. Biochem Biophys Res Commun 467: 197-203, 2015.

20. Gerrits EG, Alkhalaf A, Landman GW, van Hateren KJ, Groenier KH, Struck J, Schulte J, Gans RO, Bakker SJ, Kleefstra N and Bilo HJ: Serum peroxiredoxin 4: A marker of oxidative stress associated with mortality in type 2 diabetes (ZODIAC-28). PLoS One 2: e89719, 2014.

21. Ding Y, Yamada S, Wang KY, Shimajiri S, Guo X, Tanimoto A, Murata Y, Kitajima S, Watanabe T, Izumi H, et al: Overexpression of peroxiredoxin 4 protects against high-dose streptozotocin-induced diabetes by suppressing oxidative stress and cytokines in transgenic mice. Antioxid Redox Signal 13: 1477-1490, 2010.

22. Manta B, Hugo M, Ortiz C, Ferrer-Sueta G, Trujillo M and Denicola A: The peroxidase and peroxynitrite reductase activity of human erythrocyte peroxiredoxin 2. Arch Biochem Biophys 484: 146-154, 2009.

23. Martinez A, Peluffo G, Petruk AA, Hugo M, Piñeyro D, Demicheli V, Moreno DM, Lima A, Batthyány C, Durán R, et al: Structural and molecular basis of the peroxynitrite-mediated nitration and inactivation of trypanosoma cruzi iron-superoxide dismutases (Fe-SODs) A and B: Disparate susceptibilities due to the repair of Tyr35 radical by Cys83 in Fe-SODB through intramolecular electron transfer. J Biol Chem 289:12760-12778, 2014.

24. Cerda MB, Lloyd R, Batalla M, Giannoni F, Casal M and Policastro L: Silencing peroxiredoxin-2 sensitizes human colorectal cancer cells to ionizing radiation and oxaliplatin. Cancer Lett 388: 312-319, 2017.

25. Rostila A, Puustinen A, Toljamo T, Vuopala K, Lindström I, Nyman TA, Oksa P, Vehmas T and Anttila SL: Peroxiredoxins and tropomyosins as plasma biomarkers for lung cancer and asbestos exposure. Lung Cancer 77: 450-459, 2012.

26. Shiota M, Yokomizo A, Kashiwagi E, Takeuchi A, Fujimoto N, Uchiumi T and Naito S: Peroxiredoxin 2 in the nucleus and cytoplasm distinctly regulates androgen receptor activity in prostate cancer cells. Free Radic Biol Med 51: 78-87, 2011.

27. Zhang B, Wang Y and Su Y: Peroxiredoxins, a novel target in cancer radiotherapy. Cancer Lett 286: 154-160, 2009.

28. Kwon T, Jin KR, Lee JC, Park YH, Shin HJ, Cho S, Kang YK, Kim BY, Yoon DY and Yu DY: An important role for peroxiredoxin II in survival of A549 lung cancer cells resistant to gefitinib. Exp Mol Med 47: e165, 2015.

29. Sobral-Leite M, Wesseling J, Smit VT, Nevanlinna H, van Miltenburg MH, Sanders J, Hofland I, Blows FM, Coulson P and Patrycja G: Annexin A1 expression in a pooled breast cancer series: association with tumor subtypes and prognosis. BMC Med 13: 156, 2015.

30. Lin CY, Jeng YM, Chou HY, Hsu HC, Yuan RH, Chiang CP and Kuo MY: Nuclear localization of annexin A1 is a prognostic factor in oral squamous cell carcinoma. J Surg Oncol 97: 544-550, 2008. 
31. Faria PC, Sena AA, Nascimento R, Carvalho WJ, Loyola AM, Silva SJ, Durighetto AF, Oliveira AD, Oliani SM and Goulart LR: Expression of annexin A1 mRNA in peripheral blood from oral squamous cell carcinoma patients. Oral Oncol 46: 25-30, 2010.

32. Vago JP, Nogueira CR, Tavares LP, Soriani FM, Lopes F, Russo RC, Pinho V, Teixeira MM and Sousa LP: Annexin A1 modulates natural and glucocorticoid-induced resolution of inflammation by enhancing neutrophil apoptosis. J Leukoc Biol 92: 249-258, 2012.

33. Kang JH, Li M, Chen X and Yin XM: Proteomics analysis of starved cells revealed Annexin A1 as an important regulator of autophagic degradation. Biochem Biophys Res Commun 407: 581-586, 2011.

34. Yi B, Jing Z, Wang G, Qian G and Lu K: Annexin A1 protein regulates the expression of PMVEC cytoskeletal proteins in CBDL rat serum-induced pulmonary microvascular remodeling. J Transl Med 11: 98, 2013.

35. Thorburn A: Apoptosis and autophagy: Regulatory connections between two supposedly different processes. Apoptosis 1: 1-9, 2008.

36. Levine B and Kroemer G: Autophagy in the pathogenesis of disease. Cell 132: 27-42, 2008.
37. PLOS ONE Staff: Correction: Association of genetic markers in the BCL-2 family of apoptosis-related genes with endometrial cancer risk in a Chinese population. PLoS One 10: e0117632, 2015.

38. Coutinho-Camillo CM and Soares FA: CASP7 (caspase 7, apoptosis-related cysteine peptidase). Atlas Genetics Cytogenetics Oncology Haematology 3: 160-163, 2015.

39. Brentnall M, Rodriguez-Menocal L, Guevara RL, Cepero E and Boise LH: Caspase-9, caspase-3 and caspase-7 have distinctroles during intrinsic apoptosis. BMCCellBiol 14: 32,2013.

40. Multhoff G, Pockley AG, Schmid TE and Schilling D: The role of heat shock protein 70 (Hsp70) in radiation-induced immunomodulation. Cancer Lett 368: 179-184, 2015.

41. Yang G, Ziesch A, Hocke S, Kampmann E, Ochs S, De Toni EN, Göke B and Gallmeier E: Overexpression of heat shock protein 27 (HSP27) increases gemcitabine sensitivity in pancreatic cancer cells through S-phase arrest and apoptosis. J Cell Mol Med 2: 340-350, 2015

42. Zhang NN, Sheng SH, Chen D, et al: Expression and significance of HSP27 in tongue squamous cell carcinoma. Beijing $\mathrm{J}$ Stomatol 3: 146-148, 2010. 